\title{
GLOBAL STABILITY OF A LESLIE-GOWER-TYPE FRACTIONAL ORDER TRITROPHIC FOOD CHAIN MODEL
}

\author{
Shuvojit Mondal, Nandadulal Bairagi And Gaston M. N'GuereKatA
}

\begin{abstract}
Recently, the dynamical behaviors of a fractional order three species food chain model was studied by Alidousti and Ghahfarokhi (Nonlinear Dynamics, doi: org/10.1007/s11071-018$4663-6,2018$ ). They proved both the local and global asymptotic stability of all equilibrium points except the interior one. This work extends their work and gives proof of both the local and global stability analysis of the interior equilibrium point. Numerical examples are also provided to substantiate the analytical findings.
\end{abstract}

Mathematics subject classification (2010): 34A08, 26A33, 34K37, 44AXX.

Keywords and phrases: Fractional order differential equation, ecological model, local and global stability, bifurcation, chaos, periodic solution.

\section{REFERENCES}

[1] S. Samko, A. Kilbas, O. Marichev, Fractional Integrals and Derivatives, Theory and Applications, Gordon and Breach, Yverdon, 1993.

[2] M. C. Tripathy, D. Mondal, K. Biswas, S. SEN, Experimental studies on realization of fractional inductors and fractional order bandpass filters, Int. J. Circuit Theory and Applications. 43, 9 (2015), $1183-1196$.

[3] A. Boukhouima, K. Hattaf, N. Yousfi, Dynamics of a fractional order HIV infection model with specific functional response and cure rate, Int. J. Diff. Equations. 2017, (2017).

[4] P. J. TORVIK, R. L. BAgley, On the appearance of the fractional derivative in the behaviour of real materials, J. Appl. Mechanics. 51, 2 (1984), 294-298.

[5] J. A. Sabatier, O. P. Agrawal, J. T. Machado, Advances in fractional calculus, Dordrecht: Springer, 2007.

[6] J. T. Machado, V. Kiryakova, F. Mainardi, Recent history of fractional calculus, Commun. Nonlinear Sci. Numer. Simulat. 16, (2011), 1140-1153.

[7] R. E. Gutierrez, J. M. Rosario, J. T. Machado, Fractional Order Calculus: Basic Concepts and Engineering Applications, Math. Prob. Eng. doi:10.1155/2010/375858, 2010.

[8] S. Abbas, M. Benchohra, G. M. N'Guerekata, Topics in fractional differential equations, Springer Science \& Business Media. 27, (2012).

[9] S. DAs, Introduction to fractional calculus for scientists and engineers, Springer, 2011.

[10] M. L. RichARD, Fractional calculus in bioengineering, Redding: Begell House, 2006.

[11] E. Ahmed, A. M. A. El-S AYed, H. A. A. El-S AKA, Equilibrium points, stability and numerical solutions of fractional-order predator-prey and rabies models, J. Math. Anal. Appl. 325, (2007), 542553.

[12] S. RanaA, S. Bhattacharyaa, J. Pal, G. M. N'Guerekata, J. Chattopadhyay, Paradox of enrichment: A fractional differential approach with memory, Physica A. 392, (2013), 3610-3621.

[13] Z. CUI, Z. YANG, Homotopy perturbation method applied to the solution of fractional lotka-volterra equations with variable coefficients, J. Mod. Meth. Numer. Math. 5, (2014), 1-9.

[14] S. Mondal, N. Bairagi, A. LahiRi, A fractional calculus approach to Rosenzweig-MacArthur predator-prey model and its solution, J. Mod. Meth. Numer. Math. 8, 1-2 (2017), 66-76. 
[15] H. L. Li, L. Zhang, C. Hu, Y. L. JiAng, Z. Teng, Dynamical analysis of a fractional-order predator-prey model incorporating a prey refuge, J. Appl. Math. Comput. DOI: 10.1007/s12190-0161017-8, (2016).

[16] C. VARGAS-DE-LEON, Volterra-type Lyapunov functions for fractional-order epidemic systems, Commun. Nonlinear Sci. Numer. Simul. 24, (2015), 75-85.

[17] J. HuO, H. ZHAO, L. ZHU, The effect of vaccines on backward bifurcation in a fractional order HIV model, Nonlinear Anal. RWA. 26, (2015), 289-305.

[18] S. Mondal, A. LAhiri, N. BAiRAgi, Analysis of a fractional order eco-epidemiological model with prey infection and type 2 functional response, Math. Meth. Appl. Sci. DOI: 10.1002/mma.4490, (2017) 1-14.

[19] M. A. AzIZ-Alaoui, Study of a Leslie-Gower type titrophic population model, Chaos Solitons and Fractals. 14, (2002), 1275-1293.

[20] J. Alidousti, M. M. Ghahfarok hi, Dynamical behavior of a fractional three-species food chain model, Nonlinear Dyn. doi.org/10.1007/s11071-018-4663-6, (2018).

[21] E. Ahmed, A. M. A. El-S AYed, H. A. A. El-SAKA, On some Routh-Hurwitz conditions for fractional order differential equations and their applications in Lorenz, Rossler, Chua and Chen systems, Physics Letters A. 358, (2006), 1-4.

[22] S. Mondal, N. Bairagi, A. Lahiri, Analysis of a fractional order eco-epidemiological model with prey infection and type 2 functional response, Math. Meth. Appl. Sci. 40, 18 (2017), 6776-6789.

[23] K. Diethelm, N. J. Ford, A. D. FREed, A predictor corrector approach for the numerical solution of fractional differential equations, 2002.

[24] K. Diethelm, N. J. Ford, A. D. Freed, Detailed error analysis for a fractional Adams method, Numerical Algorithms. 36, (2004), 31-52. 